\title{
Ibrutinib dose modifications in the management of CLL
}

\author{
Camille Hardy-Abeloos ${ }^{1}$, Rachel Pinotti ${ }^{2}$ and Janice Gabrilove ${ }^{1^{*}}$
}

\begin{abstract}
Background: Ibrutinib is a Bruton tyrosine kinase inhibitor approved for the treatment of chronic lymphocytic leukemia (CLL) in 2014. Ibrutinib is often used to treat patients who are younger than the patients originally included in theclinical trials have additional unfavorable prognostic factors and suffer from additional comorbidities excluded from the original phase III trials. Our objective was to examine current clinical practices and their impact in this expanded population of CLL patients who often require adjustments in the standard prescribed dose and schedule of therapy.

Materials and methods: An extensive review of the medical literature was conducted to establish the consensus on ibrutinib dose modifications in patients with CLL. Twenty-nine studies were reviewed including fourteen clinical trials and fifteen "real-world practice" studies.

Results: The average discontinuation rate was similar between clinical trials and "real-world practice" studies though the reasons for discontinuation differed. CLL progression was a more common reason for discontinuation in clinical trial studies while toxicity was a more common reason for discontinuation in "real-world practice" studies. Some studies have suggested worse outcomes in patients requiring dose reductions in ibrutinib while others have shown no change in treatment efficacy in patients requiring dose reductions due to concomitant CYP medications or increased immunosuppression post-transplant.

Conclusion: The impact of ibrutinib dose modifications on clinical outcome remains unclear. Patients on concomitant CYP3A inhibitors should be prescribed a lower dose than the standard $420 \mathrm{mg}$ daily, in order to maintain comparable pharmacologic properties. Further research is required to establish definitive clinical practice guidelines.
\end{abstract}

Keywords: Ibrutinib, CLL, dosage, discontinuation

\section{Introduction}

In 2014, ibrutinib, a Bruton's tyrosine kinase (BTK) inhibitor, at a dose of $420 \mathrm{mg}$ po daily, was approved as second line treatment for chronic lymphocytic leukemia (CLL), based on the RESONATE landmark trial, leading to FDA approval for this indication. Soon thereafter, the RESONATE-2 trial demonstrated the efficacy of this drug, utilizing the same dose and schedule, as first line therapy of CLL. The RESONATE-2 trial excluded

\footnotetext{
* Correspondence: janice.gabrilove@mssm.edu

${ }^{1}$ Division of Hematology and Medical Oncology, Tisch Cancer Institute, Icahn School of Medicine at Mount Sinai, New York, NY, USA

Full list of author information is available at the end of the article
}

patients who were younger than 65 years of age and who had chromosome 17p13.1 deletion. Both trials excluded patients who had an Eastern Cooperative Oncology Group (ECOG) performance status more than 2, inadequate kidney function, significant neutropenia or thrombocytopenia; patients requiring Warfarin due to the increased risk of bleeding on ibrutinib; and patients requiring strong CYP3A4/5 inhibitors due to ibrutinib's metabolism by the same enzyme. Of note, patients requiring moderate or mild CYP3A inhibitors were not excluded from participation in these respective studies.

Since then, the use of ibrutinib to treat chronic lymphoid leukemia (CLL) has evolved. Currently ibrutinib is

(c) The Author(s). 2020 Open Access This article is licensed under a Creative Commons Attribution 4.0 International License, which permits use, sharing, adaptation, distribution and reproduction in any medium or format, as long as you give appropriate credit to the original author(s) and the source, provide a link to the Creative Commons licence, and indicate if changes were made. The images or other third party material in this article are included in the article's Creative Commons licence, unless indicated otherwise in a credit line to the material. If material is not included in the article's Creative Commons licence and your intended use is not permitted by statutory regulation or exceeds the permitted use, you will need to obtain permission directly from the copyright holder. To view a copy of this licence, visit http://creativecommons.org/licenses/by/4.0/ The Creative Commons Public Domain Dedication waiver (http://creativecommons.org/publicdomain/zero/1.0/) applies to the data made available in this article, unless otherwise stated in a credit line to the data. 
often used to treat patients who are younger than the patients originally included in the RESONATE and RESONATE-2 trials, respectively, have additional unfavorable prognostic factors and suffer from additional comorbidities excluded from the original phase III trials of ibrutinib. This expanded population of CLL patients, who are candidates for treatment with ibrutinib, often require adjustments in the standard prescribed dose and schedule of therapy. The purpose of this review was to examine our current knowledge of dose modifications of ibrutinib (dose reductions and/or interruption[s]) in "real-world practice" for patients with CLL and its potential clinical impact, as published in the literature.

\section{Methods}

We searched PubMed and Scopus for studies examining the real-world dose reduction and interruption of ibrutinib in patient with CLL. Only studies published in English within the last 5 years, since the RESONATE trial in 2014, were included.

To identify ibrutinib clinical trials in PubMed, the key title MeSH terms used were "Ibrutinib", "chronic lymphoid leukemia or chronic lymphocytic leukemia or CLL" sorted by best match and filtered by clinical trial published in the last 5 years. Thirty-four papers were identified, of which eight were included in the final analysis (Fig. 1). Out of the eight studies included, six were clinical trial

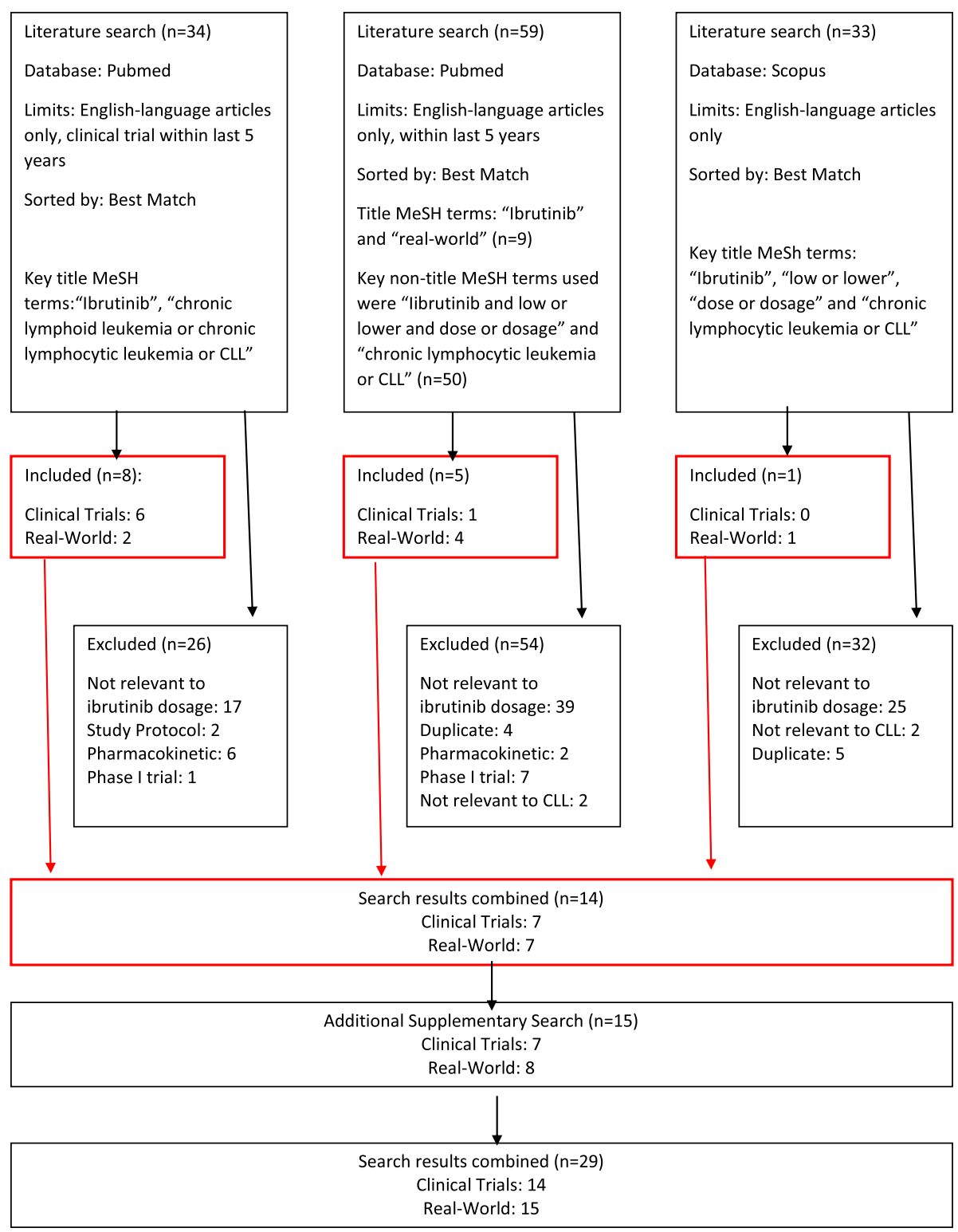

Fig. 1 Flow Chart 
papers [1-6], and two were real-world studies $[7,8]$. Out of the twenty-six papers excluded, seventeen were realworld studies not on ibrutinib dosage or discontinuation, two were study protocols, six were molecular/pharmacokinetic studies, and one was a phase 1 study.

To identify ibrutinib real-world studies in PubMed, the key title MeSH terms used were "Ibrutinib" and "real-world" sorted by best match and filtered by studies published in the last 5 years. Nine papers were identified. To broaden our search, the key non-title MeSH terms used were "Ibrutinib and low or lower and dose or dosage" and "chronic lymphocytic leukemia or CLL" sorted by best match filtered by studies published in the last 5 years. This identified fifty studies. Combining both searches, we therefore identified a total of fifty-nine studies (Fig. 1). Five papers were included in the final analysis which included one clinical trial and four realworld studies [9-13]. Out of the fifty-four studies excluded, thirty-nine were not relevant to ibrutinib dosage, four studies had been previously identified, two were pharmacokinetic studies, seven were phase I clinical trials, and two were not relevant to CLL (Fig. 1).

To identify ibrutinib clinical trial and "real-world practice" studies in Scopus, the key title MeSh terms used were "Ibrutinib", "low or lower", "dose or dosage", and "chronic lymphocytic leukemia or CLL". A total of thirty-three studies of which one "real-world practice" was included in the final analysis [14]. Out of the thirty-two studies excluded, twentyfive were not relevant to ibrutinib dosage, five had previously been identified, and two were not relevant to CLL (Fig. 1).

Additional supplementary searching, including consulting cited references, identified eight additional "real-world practice" studies [15-22] and seven clinical trial papers [23-29]. In summary, we identified twenty-nine studies including fourteen papers reporting on clinical trials (eight original papers, five papers reflecting longer-term follow-up of a retrospective trial and one sub-analysis of the RESONATE trial [2]) and fifteen "real-world" studies providing information on dose modification practice, rationale, and clinical sequelae in the context of routine clinical care (Fig. 1).

\section{Results \\ Clinical characteristics: clinical trial participants vs patients in real-world practice}

Baseline patient characteristics, including age, performance status, and chromosomal abnormalities, of patients treated in 9 respective clinical trials vs those of patients treated in the "real-world practice" setting are shown in Tables 1 and 2, respectively [1,3-11, 13-17, 24-27]. In both types of studies, ibrutinib was mainly used to treat CLL. Patients with CLL ranged from $90-100 \%$ in clinical trials vs $89-100 \%$ in "real-world practice" studies. However, in studies including both patients with treatmentnaïve CLL and relapsed disease, real-world studies reported a higher proportion of patients with relapsed disease compared to the proportion of patients with relapsed disease in clinical trial studies; 89.9\% (range 81$97.4 \%$ ) vs $62.1 \%$ (range $38.4-77 \%$ ), respectively. Ibrutinib was more often used in patients with relapsed disease in these "real-world" practice studies. Furthermore, ibrutinib was more often used in patients with poor performance status (ECOG $\geq 2$ ) in real-world studies. The majority of "real-world" practice studies included roughly a third of patients with poor performance status (ECOG $\geq 2$ ), with the exception of the report by Akhtar et al., in which a lower proportion of patients with ECOG $\geq 2$ (7\%) were included. In all the clinical trials, patients with a poor performance status, as measured by ECOG $\geq$ 2 , contributed to a very small proportion of the total number of study patients $(0-3 \%)$, with the exception of the RESONATE-2 study, which included a slightly higher proportion of patients with ECOG $\geq 2$ (8\%).

Table 1 Patient characteristics in clinical trials

\begin{tabular}{|c|c|c|c|c|c|c|c|c|c|c|}
\hline \multirow[t]{2}{*}{ 1st author } & \multirow[t]{2}{*}{ Study } & \multirow{2}{*}{$\begin{array}{l}\text { Number of } \\
\text { patients }\end{array}$} & \multirow{2}{*}{$\begin{array}{l}\text { Median } \\
\text { age } \\
\text { (range) }\end{array}$} & \multicolumn{2}{|c|}{ Therapy (\%) } & \multicolumn{2}{|c|}{ Diagnosis } & \multirow{2}{*}{$\begin{array}{l}\text { del } 11 q 22.3 \\
(\%)\end{array}$} & \multirow{2}{*}{$\begin{array}{l}\text { del 17p13.1 } \\
(\%)\end{array}$} & \multirow{2}{*}{$\begin{array}{l}\text { CYP3A45 } \\
\text { strong } \\
\text { inhibitors }\end{array}$} \\
\hline & & & & Front-line & Relapse & CLL (\%) & SLL (\%) & & & \\
\hline Byrd et al. & RESONATE & 195 & $67(30-86)$ & 0 & 100 & 95 & 5 & 32 & 32 & Excluded \\
\hline Burger et al. [3] & RESONATE-2 & 136 & 73 (65-89) & 100 & 0 & 90 & 10 & 21 & 0 & Excluded \\
\hline O'Brien et al. [5] & RESONATE-17 & 144 & $64(57-72)$ & 0 & 100 & 95 & 5 & 16 & 100 & Excluded \\
\hline Ahn et al. [6] & NCT01500733 & 86 & $66(33-85)$ & 61.6 & 38.4 & 1 & 0 & NR & 58 & NR \\
\hline Byrd et al. [25] & $\begin{array}{l}\text { PCYC } 1102 \text { phase 1b/2 } \\
\text { (NEJM 2013) }\end{array}$ & 85 & $68(37-82)$ & 0 & 100 & 96 & 4 & 36 & 33 & NR \\
\hline O'Brien et al. [24] & $\begin{array}{l}\text { PCYC } 1102 \text { phase 1b/2 } \\
\text { (Lancet 2014) }\end{array}$ & 31 & $71(65-84)$ & 100 & 0 & 94 & 6 & 3 & 6 & NR \\
\hline Byrd et al. [26] & $\begin{array}{l}\text { PCYC } 1103 \text { 3-year FU } \\
\text { (Blood 2015) }\end{array}$ & 132 & 68 (37-84) & 23 & 77 & 96 & 4 & 27 & 27 & Avoided \\
\hline Coutre et al. [4] & PCYC 1103 44-month FU & 94 & $68(37-84)$ & 29 & 71 & NR & NR & 23 & 27 & Avoided \\
\hline Chen et al. [27] & NCT02801578 & 11 & $68(52-79)$ & NR & NR & 100 & 0 & 0 & 0 & NR \\
\hline
\end{tabular}


Table 2 Patient characteristics in "real-world practice" studies

\begin{tabular}{|c|c|c|c|c|c|c|c|c|c|}
\hline \multirow[t]{2}{*}{ 1st author } & \multirow{2}{*}{$\begin{array}{l}\text { Number of } \\
\text { patients }\end{array}$} & \multirow{2}{*}{$\begin{array}{l}\text { Median age } \\
\text { (range) }\end{array}$} & \multicolumn{2}{|c|}{ Therapy (\%) } & \multicolumn{2}{|c|}{ Diagnosis } & \multirow{2}{*}{$\begin{array}{l}\text { del } 11 q 22.3 \\
(\%)\end{array}$} & \multirow{2}{*}{$\begin{array}{l}\text { del 17p13.1 } \\
(\%)\end{array}$} & \multirow{2}{*}{$\begin{array}{l}\text { CYP3A45 stron } \\
\text { inhibitors }\end{array}$} \\
\hline & & & Front-line & Relapse & $\begin{array}{l}C L L \\
(\%)\end{array}$ & $\begin{array}{l}\text { SLL } \\
(\%)\end{array}$ & & & \\
\hline Mato et al. [8] & 197 & 66 (NR) & 19 & 81 & 100 & 0 & NR & NR & Excluded \\
\hline Ysebaert et al. [10] (French cohort) & 428 & 70 (33-93) & 2.6 & 97.4 & 100 & 0 & NR & 45.1 & NR \\
\hline Winqvist et al. [11] (Swedish cohort) & 95 & $69(42-86)$ & 0 & 100 & 98 & 2 & 18 & 63 & Excluded \\
\hline Akhtar et al. [16] & 70 & $\begin{array}{l}68.0(48.4- \\
92.0)\end{array}$ & 10 & 90 & 100 & 0 & 24 & 10 & NR \\
\hline Mato et al. [13] & 391 & $68(36-96)$ & 100 & 0 & 100 & 0 & 17.1 & 29.8 & NR \\
\hline Finnes et al. [14] & 118 & $59(29-83)$ & 5.9 & 94.1 & 89 & 11 & 13 & 17 & Included \\
\hline UK CLL forum [7] & 315 & 69 (42-93) & 0 & 100 & 100 & 0 & NR & 28.3 & $N R$ \\
\hline Mato et al. [9] & 616 & 60 (22-95) & 13 & 87 & 100 & 0 & 35 & 26 & $N R$ \\
\hline $\begin{array}{l}\text { Iskierka-Jażdżewska et al. [17] (Polish } \\
\text { cohort) }\end{array}$ & 165 & $63(40-84$ & 0 & 100 & 97 & 3 & $N R$ & 18.4 & Excluded \\
\hline Mato et al. [15] & 178 & 60 (33-89) & 100 & 0 & 100 & 0 & 37 & 37 & Excluded \\
\hline
\end{tabular}

Patients with adverse cytogenetics consisting of del $11 \mathrm{q} 22.3$ or del $17 \mathrm{p} 13.1$ were variably reported in both clinical trial and real-world studies. The average proportion of people with $11 \mathrm{q}$ deletions was higher in realworld studies compared to the average proportion of people with $11 \mathrm{q}$ deletions in clinical trials $(24 \%$ vs $19.75 \%)$. In $5 / 9$ clinical trial studies and in 6/10 realworld studies, about a third (13-37\%) of CLL patients had del 11q22.3. The percentage of patients with del 17 p13.1 in clinical trials can be summarized as follows: (1) $100 \%$ in the RESONATE-17 study ( they only included patients with del 17p13.1), (2) $58 \%$ in $1 / 9$ studies [6], (3) $27-33 \%$ in $4 / 9$ studies $[1,4,25,26],(4) 6 \%$ of patients the PCYC 1102 study [24], and (5) $0 \%$ in RESONATE-2 due to exclusion and $0 \%$ in NCT02801578 study due to chance. All real-world studies included patients with del 17p13.1 except Mato et al. which did not report. The percentage of patients with del $17 \mathrm{p} 13.1$ ranged from as few as $10 \%$ [16] to as much as $45-63 \%[10,11]$ with the majority of studies $(6 / 10)$, including roughly one third (17-37\%) of patients who possessed this adverse prognostic feature $[7,9,13-15$, 17]. Overall, real-world studies had a higher proportion of people with $11 \mathrm{q}$ and $17 \mathrm{p}$ deletions. Finally, only one real-world study clearly reported the use of ibrutinib in patients on strong CYP3A4 inhibitors while all RESONATE trials excluded concomitant use of strong CYP3A4 and many studies did not report on their inclusion or exclusion. Overall, "real-world practice" studies reflected the use of ibrutinib in younger patients, with more adverse performance status and prognostic factors, as evidenced by a higher proportion of people with relapsed CLL, ECOG $\geq 2$, and with 11q and 17p deletions, and included patients on strong as well as moderate or weak CYP3A4 inhibitors and or inducers.

\section{Discontinuation of ibrutinib Clinical trials}

Discontinuation rates in the setting of formally conducted clinical trials are shown in Table $3[1,2,3,4,5,6,23,24$, $25,26,28]$. The average discontinuation rate was $32 \%$ (range 12.5-66\%). In 5/11 studies, CLL progression accounted for about half of the discontinuation rates, ranging from 40 to $54 \%$. In RESONATE-2, toxicity accounted for $64.7 \%$ of discontinuations, in the longer-term followup report of RESONATE-2 (28.5 months), toxicity, combined with death due to other causes, accounted for $78.6 \%$ of discontinuation. In the remaining 9 studies, adverse events accounted for roughly one third of the discontinuations, ranging from $22-40 \%$ [1, 4, 5, 6, 23, 24, 25, 26, 28].

In a retrospective study, Jain et al. reported reasons for discontinuation of ibrutinib in patients with CLL from 7 distinct clinical trials conducted between 2010 and 2015 [18]. The study was not included in Table 1 because the pooled analysis from 7 different clinical trials made it difficult to attribute specific patient characteristics to the individual regimens utilized. However, with 320 patients, it is the largest study to report on the rates and reasons for ibrutinib discontinuation. The discontinuation rate of $32 \%$ was similar to the $32 \%$ average discontinuation rate for the trials included in Table 3, as detailed above. Out of the patients who discontinued ibrutinib, $52 \%$ received ibrutinib monotherapy, $34 \%$ received ibrutinib with rituximab, and $14 \%$ received ibrutinib with bendamustine and rituximab. CLL progression accounted for $21 \%$ of ibrutinib discontinuations, lower than the average of $34 \%$ noted for the 11 clinical trials evaluated. The most common reason for discontinuation in this study was intolerance/toxicity (32\%) followed closely by other adverse events (31\%), respectively. 
Table 3 Discontinuation rates of ibrutinib in published clinical trials

\begin{tabular}{|c|c|c|c|c|c|c|c|c|}
\hline \multirow{3}{*}{$\begin{array}{l}1 \text { st } \\
\text { author }\end{array}$} & \multirow[t]{3}{*}{ Study } & \multirow{3}{*}{$\begin{array}{l}\text { Median duration of } \\
\text { treatment in months } \\
\text { (range) }\end{array}$} & \multirow{3}{*}{$\begin{array}{l}\text { Discontinuation } \\
\text { rate }(\%)\end{array}$} & \multicolumn{4}{|c|}{ Reason for dose discontinuation (\%) } & \multirow{3}{*}{$\begin{array}{l}\text { Dose reduction } \\
1 \text { year }(\%)\end{array}$} \\
\hline & & & & \multicolumn{3}{|c|}{ Non-relapse disease } & \multirow{2}{*}{$\begin{array}{l}\begin{array}{l}\text { Relapsed } \\
\text { disease }\end{array} \\
\mathrm{CLL} \\
\text { progression }\end{array}$} & \\
\hline & & & & $\begin{array}{l}\text { Toxicity/ } \\
\text { AE }\end{array}$ & $\begin{array}{l}\text { Death not } \\
\text { secondary } \\
\text { to CLL/AE }\end{array}$ & $\begin{array}{l}\text { Patient } \\
\text { preference/ } \\
\text { other }\end{array}$ & & \\
\hline $\begin{array}{l}\text { Byrd et al. } \\
\text { [1] }\end{array}$ & RESONATE & $8.6(0.2-16.1)$ & 13.8 & 29.6 & 29.6 & 7.4 & 33.3 & NR \\
\hline $\begin{array}{l}\text { Byrd et al. } \\
{[1]}\end{array}$ & RESONATE long-term FU & $41(0.2-50.1)$ & 53.8 & 22 & 11.4 & 16.1 & 50.5 & 6 \\
\hline $\begin{array}{l}\text { Burger et al. } \\
\text { [3] }\end{array}$ & RESONATE-2 & $17.4(0.7-24.7)$ & 12.5 & 64.7 & 17.6 & 5.9 & 11.8 & NR \\
\hline Barr et al. & RESONATE-2 long term FU & $28.5(0.7-35.9)$ & 20 & 78.6 & & 7.1 & 14.3 & 9 \\
\hline $\begin{array}{l}\text { O'Brien et al. } \\
\text { [23] }\end{array}$ & RESONATE-17 & $11.5(11.1-13.8)$ & 50 & 33 & & 20 & 47 & 7 \\
\hline $\begin{array}{l}\text { Ahn et al. } \\
{[6]}\end{array}$ & Ahn et al. & 4.8 years ( $4-6$ years) & 43 & 13 & 11 & 22 & 54 & NR \\
\hline $\begin{array}{l}\text { Byrd et al. } \\
{[1]}\end{array}$ & NEJM 2013-PCYC 1102 & $20.9(0.7-26.7)$ & 36 & 22.5 & 0 & 42 & 35.5 & NR \\
\hline $\begin{array}{l}\text { O'Brien et al. } \\
\text { [24] }\end{array}$ & $\begin{array}{l}\text { Lancet 2014-PCYC } 1102 \\
\text { phase } 1 \mathrm{~b} / 2\end{array}$ & $22.1(18.4-23.2)$ & 16 & 40 & NR & 40 & 20 & NR \\
\hline $\begin{array}{l}\text { Byrd et al. } \\
{[1]}\end{array}$ & PCYC 1103 & $25(0.3-45)$ & 40 & 28 & $N R$ & 30 & 42 & NR \\
\hline $\begin{array}{l}\text { Coutre et al. } \\
{[4]}\end{array}$ & PCYC 1103 & $30(1-44)$ & 34 & 37 & 0 & 25 & 28.1 & NR \\
\hline O'Brien et al. & PCYC 1103 & $62(1-75)$ & 66 & 31 & NR & 27.6 & 40 & NR \\
\hline
\end{tabular}

Similarly, a study by Maddocks et al. was not included in Tables 1 and 3, because it was a pooled analysis of discontinuation rates derived from 4 different clinical trial participants treated with ibrutinib monotherapy or ibrutinib with ofatumumab [19]. The investigators reported a similar rate of discontinuation (25\%), similar rates of toxicity/other adverse events leading to discontinuations (59\%), and similar rate of CLL progression (17\%) to the rates found in the Jain et al. study. In addition, 23\% of patients discontinued ibrutinib due to Richter's transformation.

In the RESONATE long-term follow-up [28], RESONATE-2 long-term follow-up [2], and PCYC1103 5-year follow-up [23], the prevalence of adverse events leading to dose reduction was analyzed over time. The RESONATE long-term follow-up showed that the prevalence of adverse events leading to dose reduction remained consistent over time $(6 \%, 9 \%, 4 \%$, and $7 \%$ over years 0 to 1,1 to 2,2 to 3 , and 3 to 4 , respectively). The RESONATE-2 long-term follow-up and PCYC-1103 5-year follow-up showed that dose discontinuations and dose reductions resulting from adverse events occurred more frequently during the first year and tended to decrease over time (9\% within 1 st year, $5 \%$ within 2 nd year, $4 \%$ after 2 nd year ) on ibrutinib monotherapy [23, 28].

\section{"Real-world practice" studies}

Discontinuation rates reported in real-world studies are shown in Table 4 [7, 9-11, 13-17]. The average discontinuation rate was $33.5 \%$ (range14.5-43\%). CLL progression accounted for almost half of the discontinuation rates observed in one study [11]. In 5/9 studies, adverse events accounted for over half of the discontinuations ranging from $50.2-63.1 \%[7,9,13-15]$.

William et al. analyzed the reasons for ibrutinib discontinuation in patients with non-Hodgkin lymphoma (NHL) and CLL [12]. We did not include this study in Table 2 given the more diverse patient population with reported data combining both CLL and NHL patients. However, patients with CLL represented the majority of subjects included in this large retrospective cohort, with 115 out of the 170 patients diagnosed with CLL. In this study, the discontinuation rate $(30 \%)$ for the entire patient population as a whole was comparable to the rate reported in our 8 other real-world studies which included only patients with CLL. Disease progression (33\%) and adverse events (37.2\%) as reasons for 
Table 4 Discontinuation rates of ibrutinib in "real-world practice" studies

\begin{tabular}{|c|c|c|c|c|c|c|c|c|}
\hline \multirow[t]{3}{*}{ 1st author } & \multirow{3}{*}{$\begin{array}{l}\text { Median duration of } \\
\text { treatment (months) }\end{array}$} & \multirow{3}{*}{$\begin{array}{l}\text { Discontinuation } \\
\text { rate }\end{array}$} & \multicolumn{5}{|c|}{ Reason for dose discontinuation } & \multirow{3}{*}{$\begin{array}{l}\text { Dose } \\
\text { reduction over } 1 \text { year (\%) }\end{array}$} \\
\hline & & & \multicolumn{3}{|c|}{ Non-relapse disease } & \multicolumn{2}{|c|}{ Relapsed disease } & \\
\hline & & & $\begin{array}{l}\text { Toxicity/ } \\
\text { AE }\end{array}$ & $\begin{array}{l}\text { Death not } \\
\text { secondary } \\
\text { to CLL/AE }\end{array}$ & $\begin{array}{l}\text { Patient } \\
\text { preference/ } \\
\text { other }\end{array}$ & $\begin{array}{l}\text { CLL } \\
\text { progression }\end{array}$ & $\begin{array}{l}\mathrm{CLL} \\
\text { transformation }\end{array}$ & \\
\hline $\begin{array}{l}\text { Ysebaert et al. } \\
\text { [10] (French } \\
\text { cohort) }\end{array}$ & $3(1-10)$ & 14.5 & 37 & 35 & 13 & 15 & & $N R$ \\
\hline $\begin{array}{l}\text { Winqvist et al. } \\
\text { [11] (Swedish } \\
\text { cohort) }\end{array}$ & $27(0.6-38)$ & 24 & 43 & NR & 14 & 43 & & 22 \\
\hline Akhtar et al. [16] & 21.9 & 40 & 25 & NR & 22 & 32 & 21 & 31.3 \\
\hline Mato et al. [9] & $13.8(1-76)$ & 24 & 60 & 3.2 & 14.8 & 12.8 & 9.6 & 17.4 \\
\hline Finnes et al. [14] & 13 & 20.3 & 58 & NR & $N R$ & 25 & 16.7 & 21.2 \\
\hline $\begin{array}{l}\text { UK CLL forum } \\
\text { [7] }\end{array}$ & 16 & 26.3 & 55 & 3.6 & 7.2 & 16.9 & 16.9 & 26 \\
\hline Mato et al. [9] & $17(1-60)$ & 24,43 & $\begin{array}{l}63.1 \\
50.2\end{array}$ & $5.3,12.1$ & $10.5,6.7$ & $15.8,20.9$ & $5.3,4.6$ & 15,20 \\
\hline $\begin{array}{l}\text { Iskierka- } \\
\text { Jażdżewska } \\
\text { et al. [17] (Polish } \\
\text { Cohort) }\end{array}$ & $9.5(0.1-22.2)$ & 19.4 & 9.7 & NR & 2.4 & 7.3 & & NR \\
\hline Mato et al. [15] & $5(0.25-41)$ & 100 & 51 & NR & 13 & 28 & 8 & 11 \\
\hline
\end{tabular}

discontinuation were lower in this study respectively than that observed for other real-world CLL only studies, as detailed above. The actual number of CLL patients that contributed to these rates of discontinuation is unfortunately not provided. Overall, the reasons for ibrutinib discontinuations differed between patients in clinical trials vs real-world studies with more patients discontinuing ibrutinib due to adverse events in realworld studies and more patients discontinuing ibrutinib due to progression of disease in clinical trials.

\section{Ibrutinib dosing in CLL (clinical trial and clinical practice setting) post allogeneic stem cell transplant}

Little is known about the use of ibrutinib in patients with relapsed CLL following allogeneic hematopoietic cell transplant (HCT). Ryan et al. reported on the tolerability of ibrutinib in 27 patients with relapsed CLL ollowing allogeneic transplantation [20]. Sixteen patients, treated in the context of 4 separate multi-centered trials, and an additional 11 patients treated at Stanford University as part of routine care were included in the analysis. All patients received $420 \mathrm{mg}$ of ibrutinib daily, except for 2 patients in the clinical trial group who received $840 \mathrm{mg}$ daily. For the 16 patients treated on clinical trials, the median duration of ibrutinib therapy was 19 months (range 0.4-39 months) with 14 patients treated for longer than 12 months. At the time of data cutoff, the ibrutinib discontinuation was $31 \%$. Reasons for discontinuation included adverse events (12.5\%), progression (12.5\%), and withdrawal of consent (1). In the
11 patients treated at Stanford University post-transplant as part of routine clinical practice, the median duration of ibrutinib treatment of 8.4 months (range 0.5-21.4) with $45 \%$ of patients discontinuing therapy at the time of this analysis. No dose adjustments were noted in either the clinical trial or clinical practice setting.

\section{Discontinuation of ibrutinib: summary of clinical trials vs real-world studies}

In all clinical trials, patients received oral ibrutinib (at a dose of $420 \mathrm{mg}$ once daily) until disease progression or the occurrence of adverse events. Adverse events led to dose reductions during the 1st year of treatment in 5$10 \%$ of patients (average 7\%). In real-world studies, adverse events led to dose reductions during the 1st year of treatment in a slightly larger group of individuals $(11-31.3 \%)$.

\section{Dose reduction of ibrutinib}

A low incidence (6-9\%) of dose reductions after being on treatment for more than a year was observed in 3/9 clinical trials $[5,28,29]$. In the long-term follow-up study of patients enrolled on the RESONATE-2, the prevalence of dose reductions appeared to decrease over time with a median follow-up of 28.5 months. In all clinical trials, patients received oral ibrutinib (at a dose of $420 \mathrm{mg}$ once daily) until disease progression or the occurrence of adverse events. Adverse events led to dose 
reductions during the 1st year of treatment in $5-10 \%$ of patients (average 7\%).

Dose reductions over the first year of therapy were observed more frequently (11-31.3\%) in 7/9 "real-world practice" studies $[7,8,11,13,14,15,16]$. With a median follow-up of 27 months comparable to the median follow-up of the long-term RESONATE-2 study, Winqvist et al. reported $22 \%$ of patients whose ibrutinib dose was reduced over their first year over therapy compared to $9 \%$ of patients in the long-term RESONATE-2 study. In one study, a higher proportion of dose reductions were noted to occur earlier (within 3 months of treatment initiation) [16].

One "real-world practice" study reported that the prevalence of dose reductions decreased over time with a median follow-up of 21.9 months, comparable to that reported for the RESONATE-2 clinical trial [16].The most common reasons for ibrutinib dose reduction, in two of the real-world studies, were cytopenias and infection $[11,16]$.

\section{Impact of ibrutinib dose adjustments}

Barr et al. performed a retrospective analysis of the clinical impact of ibrutinib dose adherence in 195 patients from the RESONATE trial [2]. In this trial, patients whose course of therapy deviated little from the planned regimen, and who adhered closely to the prescribed regimen, referred to as planned dose intensity $(n=155$ patients) were reported to have an improved PFS as compared to those individuals who required either prolonged discontinuation of ibrutinib or for whom the planned dose intensity was not maintained $(n=38$ patients) due largely to adverse events and prolonged toxicity. Although not statistically significant, these small retrospectively compared groups differed with regard to Rai stage of disease, number of prior therapies, and creatinine clearance. Despite differences in renal function, no comparison in the pharmacokinetics of ibrutinib was provided between the two groups. Since ibrutinib is cleared by the kidney, one might reasonably postulate that in patients receiving the planned dose of ibrutinib, the area under the curve would be greater for patients with impaired renal function as compared to those with normal renal function, enhancing their predisposition to untoward toxicity. This in turn would make it difficult for patients to receive therapy, leading to a worse progression free survival (PFS) as opposed to the reduced dose in and of itself. Unfortunately, in this study, no information was provided for AUC as a function of creatinine clearance. The potential for the introduction of this type of confounder, given the hypothesis generating analysis, makes it difficult to know whether the prolonged need to withhold therapy due to unacceptable toxicity is the causative factor as opposed to the lack of maintaining dose intensity, as a plausible explanation. This in turn suggests that the avoidance of toxicity in the first place, through the use of an appropriately adjusted dose based on renal function, to achieve the desired area under the curve might have enabled patients to have an equally good PFS. This hypothesis is supported by the reported observation that eleven of twenty-six patients who restarted ibrutinib after developing progressive disease while having their dose of ibrutinib held were without clinical progression for a period of time (> 6.5 months). In addition, investigators also found that patients missing $\geq 8$ consecutive days of ibrutinib had a shorter median PFS vs those missing $<8$ days (10.9 months vs not reached).

Retrospective observational studies conducted in the context of "real-world practice" have attempted to address the impact of dose modifications on outcome with less success, given the inherent potential for selection bias and the introduction of confounders. A "real-world practice" study conducted by UK CLL Forum attempted to examine the role of ibrutinib dosing in routine clinical practice on progression free survival and overall survival [7]. In this study, clinicians were provided the opportunity to contribute anonymized data through an established database. Data from three hundred and fifteen patients from 63 medical centers across the UK was collected. Data for all parameters assessed was not available on all patients; however, the median number of prior therapies was 2, with $83.5 \%$ of patients having FISH + for 17pdeletion, consistent with a higher risk group of patients. In this cohort, 83 patients discontinued therapy at the end of 1 year, predominantly for progression of disease, resulting in a poor overall survival, as anticipated. To better delineate the role of dose modifications within the first year of treatment, the investigators divided their cohort into three respective groups: group A who received standard dose ibrutinib with no dose reductions and no treatment breaks of $>14$ days, group $\mathrm{B}$ who received any dose reduction but no treatment breaks of $>14$ days, and group $C$ who had ibrutinib therapy interrupted for $>14$ days with or without dose modifications. Median follow-up was 16 months. No difference in disease free survival (DFS) or overall survival (OS) was observed between groups A and B, suggesting that dose modification of ibrutinib in and of itself did not portend an adverse outcome; however, $42 / 92$ patients in group $C$, who were identified to have had ibrutinib withheld for $>14$ days, had a much poorer DFS and OS, suggesting that this modification in dosing, related to the inability to deliver the needed treatment, is associated with a poor outcome in this context. To further delineate the impact of dosing on outcome, the investigators conducted a post 1-year analysis of all patients in group A, B, and C, respectively. In this prospective analysis, patients who had dose reductions in the first year (group B) had no 
difference in DFS and OS from patients who received the standard regimen (group A). Furthermore, post 1-year survival did not appear to be affected by dose reductions (C1) but was compromised by temporary and permanent breaks in therapy. These data suggest that other factors, as yet to be determined, related to the need to stop ibrutinib therapy are of greater impact on outcome than modifications of ibrutinib dosing per se.

In a second retrospective study, William et. al. attempted to evaluate the impact of ibrutinib dose reductions and interruptions on outcomes in patients with CLL (51\% high risk) and NHL [12]. In the CLL cohort, $29 \%$ of patients had a reduction in dose, and $57.6 \%$ had at least one transient dose interruption (of any length) over the study period. Median follow-up time was 14.28 months (range $0.36-65.77$ months). These investigators attempted to assess the impact of dose adherence within the first 8 weeks of treatment, defining a dose adherence to the expected treatment regimen of more or less than $80 \%$. Taking this approach, the investigators reported that CLL patients, who had a dose adherence to the standard regimen of ibrutinib of $<80 \%$ within that 8 -week period, experienced a worse PFS; however, the number of patients this reflects out of the 115 CLL patients and their respective characteristics or reasons for non-adherence, included in the analysis is not provided, making this difficult to discern the real impact of dose modifications itself as opposed to being a marker of other adverse features, leading to poorer outcomes.

In a third retrospective study, Mato et al. attempted to evaluate the impact of age and del 17p13.1 on dose reductions in patients with CLL $[13,15]$. This study included patients $<65$ years old and with del 17p13.1 who had been excluded from RESONATE-2 trial. Median follow-up was 13.8 months (range 1-76 months). Age was associated with greater likelihood of initial and on treatment ibrutinib dose reduction with older patients more likely to start at a dose below $420 \mathrm{mg}$ or to have their dose reduced during treatment to achieve steady state. The presence of del 17p13.1, however, did not affect the starting dose or on treatment dose reductions. In total, about $7 \%$ of patients required an initial reduced dose, and $17 \%$ required a dose reduction during treatment. As per the Williams study, investigators attempted to evaluate the impact of ibrutinib dose reduction on PFS. They reported a worse 12-month PFS in patients receiving a reduced dose of ibrutinib, although the reason for reducing the dose was not reported. Patients comorbidity index, prior treatments, renal function, and other inherent patient characteristics could have contributed to patients requiring a dose reduction leading to a worse outcome. Given these numerous possible cofounders, the association reported does not establish a causal relationship between reduced ibrutinib dose and PFS.
Finally, a pilot study by Chen et al. attempted to evaluate the impact of reductions in ibrutinib dosing on Bruton tyrosine kinase (BTK) levels and expression [27]. Eleven patients received $420 \mathrm{mg} /$ day in cycle $1280 \mathrm{mg} /$ day in cycle 2, and $140 \mathrm{mg} /$ day in cycle 3 . In this study, the investigators demonstrated that total BTK protein decreased over the course of the 3 cycles, leading to a similar BTK occupancy with a reduced dose of ibrutinib as well as comparable pharmacodynamic and biological properties. Since BTK occupancy and biological activity is preserved at lower doses of ibrutinib, this study suggests that alterations in treatments through dose interruptions and reductions are likely not the root cause for worse clinical outcomes in patients.

Impact of CYP34A inducers/inhibitors on ibrutinib dosing Ibrutinib is extensively metabolized and eliminated by Cytochrome P450 3A (CYP3A). For this reason, the concomitant use of ibrutinib and CYP3A inhibitor and inducers could potentially promote enhanced ibrutinib toxicity or reduced efficacy, respectively. Because of the potential for adverse effects due to drug interactions, the concomitant use of strong CYP3A inhibitors was not permitted in the RESONATE and RESONATE-2 trials; however, mild and moderate CYP3A inhibitors were permitted. CLL more commonly affects older adults who often have comorbid conditions, requiring the use of medications that alter CYP3A metabolism. In addition, patients undergoing hematopoietic stem cell transplantation (HSCT) are often treated with complex medical regimens including CYP 3A4 inhibitors/substrates which may impact the bioavailability of ibrutinib. To this end, Finnes et al. evaluated concomitant medication use in 118 ibrutinib-treated CLL patients, in the clinical practice setting at the Mayo Clinic [14]. Ninety percent of this patient cohort had relapsed/refractory CLL (90\%) with a median age of 59 (range 29-83). In anticipation of starting ibrutinib 21/118 CLL, patients (16\%) were found to be on treatment with either a moderate or strong CYP3A inhibitor or inducer. As a result, prior to the initiation of ibrutinib, patients had either an adjustment in their concomitant medication to avoid drug interactions [5] or had dose modifications based on predicted changes in and preservation of desired pharmacokinetic properties associated with ibrutinib therapeutic responses. To achieve ideal pharmacokinetics while either remaining on or requiring the addition of concomitant medications known to alter CYP3A functional activity, the following adjustments in ibrutinib dose were made as follows: $140 \mathrm{mg}$ once every other day (strong CYP3A inhibitors) and $140 \mathrm{mg}$ once a day (moderate CYP3A inhibitors). In this study, based upon dosing to achieve desired pharmacokinetic properties, no difference in discontinuation rates of ibrutinib at 12 months or in the 18-month PFS between patients on 
medications known to impact CYP3A activity versus those who did not was observed. In addition, no difference in time to ibrutinib discontinuation was noted [14].

To better predict appropriate dosing recommendations for patients receiving concomitant moderate to strong CYP3A inhibitors, Zwart and colleagues developed a physiologically based pharmacokinetic model (PBPK) [22]. Using ketoconazole as a strong CYP3A inhibitor and rifampin as a strong CYP3A inducer prototypes respectively, this population-based simulation PBPK model, additionally validate by clinically observable data (healthy volunteers), was able to predict the impact of specific drug-drug interactions leading to US, Canadian, and European regulatory agency dosing recommendations for ibrutinib in the context of drugs that impact CYP3A functional activity. These recommendations include the avoidance of strong and moderate CYP3A inhibitors whenever possible, when using ibrutinib or, if unavoidable, lowering the dose of ibrutinib to $140 \mathrm{mg}$ po daily. Similarly, based on this study, the use of strong CYP3A inhibitors was discouraged, due to the likelihood of rendering ibrutinib ineffective. To confirm these established dosing recommendations and to shed additional light on the potential for drug-drug interactions between ibrutinib and moderate to strong CYP3A inhibitors, de Jong et. al. studied the impact of erythromycin and voriconazole and moderate and strong CYP3A inhibitor prototypes respectively, on the pharmacokinetics of $140 \mathrm{mg}$ of ibrutinib, in the context of a multicenter phase I study in 26 patients with low grade B cell malignancies including 14 patients with CLL (53.8\%) [21]. This study demonstrated that ibrutinib $140 \mathrm{mg}$ administered in combination with voriconazole or erythromycin provided pharmacological levels of drug comparable to that observed for patients treated with $560 \mathrm{mg}$ of ibrutinib alone, doses routinely used in patients with marginal zone lymphoma, and higher than the exposure usually observed with the standard dose of ibrutinib (420 mg daily), utilized in patients with CLL, suggesting room for further reduction in ibrutinib dosing, to achieve comparable biologically and clinically effective levels.

These studies collectively suggest that adjustment of ibrutinib dosing is warranted in the context of the need for co-administration of moderate to strong CYP3A inhibitors for comorbid conditions, to achieve pharmacologically comparable therapeutic levels of ibrutinib, thereby maintaining disease specific treatment efficacy while avoiding the potential for added toxicity that standard dosing would likely ensue.

\section{Discussion}

From our review of both clinical trials and real-world practice studies to date, we can conclude that patients receiving strong or moderate CYP3A inhibitors, defined by the US, Canadian, and European regulatory agency, should be treated with $140 \mathrm{mg}$ or $280 \mathrm{mg}$ of ibrutinib respectively [22]. Despite differences in patient characteristics, the average discontinuation rate of ibrutinib was similar between clinical trials and "real-world practice" as follows: $32 \%$ (range $12.5-66 \%$ ) vs $33.5 \%$ (range $14.5-43 \%$ ), respectively. However, the reason for discontinuation differed with toxicity being a more common reason for discontinuation in "real-world practice" compared to clinical trials $[1-4,6,7,9-11,13-17,23-26,28]$. In the largest real-world study including 616 patients with CLL treated with ibrutinib, the three most common toxicities were arthralgia (41.6\%), atrial fibrillation (25\%), and rash (16.7\%) [9]. More patients had adverse events leading to ibrutinib dose reductions in "real-world practice" studies compared to clinical trial studies ( $7 \%$ vs $24 \%$ ). The most common adverse events causing ibrutinib dose reductions were infection and cytopenia in two real-world studies $[11,16]$. In addition, we can hypothesize, based on differences in performance status as a surrogate, that real-world patients likely suffered from additional comorbidities, in particular abnormal liver function, normally excluded in the context of rigorous clinical trials, possibly contributing to the increase in side effects observed. Unfortunately, this has not been systematically reported to enable one to clearly prove this hypothesis. Both clinical trials and realworld studies showed that the prevalence of dose reductions decreased over time. This is possibly due to the fact that the majority of adverse events occur earlier on in treatment $[2,6]$. The key differences in ibrutinib dosing between clinical trials and "real-world practice" studies are summarized in Table 5.

Given the current recommended guidelines to reduce ibrutinib dosing, when patients require the concomitant use of a moderate or strong CYP3A inhibitor, it is tempting to speculate on the potential cost savings that could be realized, if patients receiving ibrutinib therapy were to be placed routinely on an inexpensive and otherwise well tolerated CYP3A inhibitor. However, the safety

Table 5 Summary of ibrutinib dose discontinuation rates or modification in clinical trials vs "real-world practice" studies

\begin{tabular}{lll}
\hline & Clinical trial & Real-world \\
\hline Average discontinuation rate due to toxicity & $36.3 \%$ (range 13-64.7\%) & $45.2 \%$ (range 9.7-63.1\%) \\
Average discontinuation rate due to relapsed disease & $34.2 \%$ (range 11.8-50.5\%) & $25.5 \%$ (range 12.8-53\%) \\
Average dose reduction over 1 year & $7.3 \%$ (range 6-9\%) & $20.5 \%$ (range 11-31.3\%) \\
\hline
\end{tabular}


of this approach, the long-term tolerability, and the clinical efficacy of ibrutinib therapy in this context has not been formally evaluated. The conduct of a well-designed prospective clinical trial, to evaluate this possible therapeutic strategy, will be needed before such an approach could be considered in clinical practice.

The clinical impact of dose modifications remains unclear. Patients who are not able to maintain the dose due to either prolonged dose reductions or interruptions in treatment appear to have worse outcomes though it remains unclear whether it is due to the patient's inability to receive the standard dose, or whether it results from the dose modification itself $[2,7,12]$. At the current time, best practice dosing recommendations include reduction in the ibrutinib dose for patients receiving moderate or strong CYP3A inhibitors, as detailed above and when treating patients with liver disease comorbidity [30]. Based upon this review, these dosing recommendations as well as clinical judgement, should guide dosing parameters in an effort to optimally balance clinical therapeutic efficacy and safety.

Some studies have shown worse outcomes in patients requiring dose reductions while others have shown no decrease in treatment efficacy $[7,12,13,15]$. These controversial findings highlight the numerous confounders that potentially impact ibrutinib dose modifications and outcomes, rendering it difficult to draw any definitive dosing recommendations at this time.

\section{Conclusion}

The impact of ibrutinib dose modifications on clinical outcome remains unclear. Patients on concomitant CYP3A inhibitors should be prescribed a lower dose than the standard $420 \mathrm{mg}$ daily, in order to maintain comparable pharmacologic properties. Modification of ibrutinib doses in real-world practice reflects an increase in side effects observed as compared to that reported in clinical trials. This likely reflects differences in patient characteristics and comorbidities among real-world patients as opposed to those enrolled onto clinical trials. Further research is required to establish definitive clinical practice guidelines.

\section{Abbreviations \\ BTK: Bruton's tyrosine kinase; CLL: Chronic lymphocytic leukemia; PBPK: Physiologically based pharmacokinetic; FISH: Fluorescence in-situ hybridization; CYP: Cytochrome P450; ECOG: Eastern Cooperative Oncology Group; MeSH: Medical subject headings}

\section{Acknowledgements}

Not applicable

\section{Authors' contributions}

CA and JG were both instrumental in the design of the scoping review. CA and RP conducted the literature searches. CA and JG analyzed all the published literature derived from searches, and summation of all papers selected to be included in the review, summarizing and tabulating data derived from published manuscripts and drafting the manuscript. JG played a key role in not only drafting the scoping review but in substantially revising it and approving the final version for submission. RP provided library science and design expertise for published literature searches to enable the retrieval of appropriate manuscripts for this scoping review. The author(s) read and approved the final manuscript.

\section{Author's information}

Janice L. Gabrilove, MD, FACP

The James F. Holland Professor of Medicine and Oncological Sciences Associate Director, Education \& Training

The Tisch Cancer Institute, a National Cancer Institute-designated Cancer Center

Director, Clinical Research Education Programs

(CRTP, Master of Science (MSCR) \& PhD in Clinical Research)

Co-Director, KL2 Scholars \& PORTAL (MD/MSCR) Programs

Icahn School of Medicine at Mount Sinai \& Graduate School of Biomedical

Sciences

212-241-9650

\section{Funding}

This was an unfunded scoping review

Availability of data and materials

Not applicable

Ethics approval and consent to participate

These issues are not applicable to this scoping review

Consent for publication

No applicable

\section{Competing interests}

The authors declare they have no competing interests

\section{Author details}

${ }^{1}$ Division of Hematology and Medical Oncology, Tisch Cancer Institute, Icahn School of Medicine at Mount Sinai, New York, NY, USA. ${ }^{2}$ Library Education and Research Services, Icahn School of Medicine at Mount Sinai, New York, NY, USA.

Received: 15 December 2019 Accepted: 1 April 2020

Published online: 05 June 2020

\section{References}

1. Byrd JC, Brown JR, O'Brien S, et al. Ibrutinib versus ofatumumab in previously treated chronic lymphoid leukemia. The New England journal of medicine. 2014;371:213-23.

2. Barr PM, Brown JR, Hillmen $\mathrm{P}$, et al. Impact of ibrutinib dose adherence on therapeutic efficacy in patients with previously treated CLL/SLL. Blood. 2017; 129:2612-5.

3. Burger JA, Tedeschi A, Barr PM, et al. Ibrutinib as initial therapy for patients with chronic lymphocytic leukemia. The New England journal of medicine. 2015:373:2425-37.

4. Coutre SE, Furman RR, Flinn IW, et al. Extended treatment with single-agent ibrutinib at the $420 \mathrm{mg}$ dose leads to durable responses in chronic lymphocytic leukemia/small lymphocytic lymphoma. Clin Cancer Res. 2017; 23:1149-55.

5. O'Brien S, Jones JA, Coutre SE, et al. Ibrutinib for patients with relapsed or refractory chronic lymphocytic leukaemia with 17p deletion (RESONATE-17): a phase 2, open-label, multicentre study. Lancet Oncol. 2016;17:1409-18.

6. Ahn IE, Farooqui MZH, Tian X, et al. Depth and durability of response to ibrutinib in CLL: 5-year follow-up of a phase 2 study. Blood. 2018;131:2357-66.

7. Forum UC. Ibrutinib for relapsed/refractory chronic lymphocytic leukemia: a UK and Ireland analysis of outcomes in 315 patients. Haematologica. 2016; 101:1563-72.

8. Mato AR, Timlin C, Ujjani C, et al. Comparable outcomes in chronic lymphocytic leukaemia (CLL) patients treated with reduced-dose ibrutinib: results from a multi-centre study. Br J Haematol. 2018;181:259-61.

9. Mato AR, Nabhan C, Thompson MC, et al. Toxicities and outcomes of 616 ibrutinib-treated patients in the United States: a real-world analysis. Haematologica. 2018;103:874-9. 
10. Ysebaert L, Aurran-Schleinitz T, Dartigeas C, et al. Real-world results of ibrutinib in relapsed/refractory CLL in France: early results on a large series of 428 patients. Am J Hematol. 2017;92:E166-e168.

11. Winqvist $M$, Asklid $A$, Andersson $P$, et al. Real-world results of ibrutinib in patients with relapsed or refractory chronic lymphocytic leukemia: data from 95 consecutive patients treated in a compassionate use program. A study from the Swedish Chronic Lymphocytic Leukemia Group. Haematologica. 2016;101:1573-80.

12. Williams AM, Baran AM, Casulo C, et al: Ibrutinib dose adherence and therapeutic efficacy in non-hodgkin lymphoma: a single-center experience. Clinical Lymphoma Myeloma and Leukemia, 2018.

13. Mato $A R$, Roeker $L E$, Allan $J N$, et al. Outcomes of front-line ibrutinib treated CLL patients excluded from landmark clinical trial. American Journal of Hematology. 2018;93:1394-401.

14. Finnes HD, Chaffee KG, Call TG, et al. Pharmacovigilance during ibrutinib therapy for chronic lymphocytic leukemia (CLL)/small lymphocytic lymphoma (SLL) in routine clinical practice. Leuk Lymphoma. 2017;58:1376-83.

15. Mato AR, Nabhan C, Barr PM, et al. Outcomes of CLL patients treated with sequential kinase inhibitor therapy: a real world experience. Blood. 2016;128: 2199-205.

16. Akhtar OS, Attwood K, Lund I, et al. Dose reductions in ibrutinib therapy are not associated with inferior outcomes in patients with chronic lymphocytic leukemia (CLL). Leuk Lymphoma. 2019:1-6.

17. Iskierka-Jażdżewska E, Hus M, Giannopoulos K, et al. Efficacy and toxicity of compassionate ibrutinib use in relapsed/refractory chronic lymphocytic leukemia in Poland: analysis of the Polish Adult Leukemia Group (PALG). Leukemia \& Lymphoma. 2017;58:2485-8.

18. Jain $\mathrm{P}$, Thompson PA, Keating $\mathrm{M}$, et al. Long-term outcomes for patients with chronic lymphocytic leukemia who discontinue ibrutinib. Cancer. 2017; 123:2268-73.

19. Maddocks KJ, Ruppert AS, Lozanski G, et al. Etiology of ibrutinib therapy discontinuation and outcomes in patients with chronic lymphocytic leukemia. JAMA Oncol. 2015:1:80-7.

20. Ryan CE, Sahaf B, Logan AC, et al. Ibrutinib efficacy and tolerability in patients with relapsed chronic lymphocytic leukemia following allogeneic HCT. Blood. 2016;128:2899-908.

21. de Jong J, Hellemans P, De Wilde S, et al. A drug-drug interaction study of ibrutinib with moderate/strong CYP3A inhibitors in patients with B-cell malignancies. Leuk Lymphoma. 2018:59:2888-95.

22. de Zwart L, Snoeys J, De Jong J, et al. Ibrutinib dosing strategies based on interaction potential of CYP3A4 perpetrators using physiologically based pharmacokinetic modeling. Clin Pharmacol Ther. 2016;100:548-57.

23. O'Brien SM, Furman RR, Coutre SE, et al. Five-year experience with single-agent ibrutinib in patients with previously untreated and relapsed/refractory chronic lymphocytic leukemia/small lymphocytic leukemia. Blood. 2016;128:233.

24. O'Brien S, Furman RR, Coutre SE, et al. Ibrutinib as initial therapy for elderly patients with chronic lymphocytic leukaemia or small lymphocytic lymphoma: an open-label, multicentre, phase 1b/2 trial. Lancet Oncol. 2014;15:48-58.

25. Byrd JC, Furman RR, Coutre SE, et al. Targeting BTK with ibrutinib in relapsed chronic lymphocytic leukemia. N Engl J Med. 2013;369:32-42.

26. Byrd JC, Furman RR, Coutre SE, et al. Three-year follow-up of treatmentnaive and previously treated patients with CLL and SLL receiving singleagent ibrutinib. Blood. 2015;125:2497-506.

27. Chen LS, Bose P, Cruz ND, et al. A pilot study of lower doses of ibrutinib in patients with chronic lymphocytic leukemia. Blood. 2018;132:2249-59.

28. Byrd JC, Hillmen P, O'Brien S, et al. Long-term follow-up of the RESONATE phase 3 trial of ibrutinib vs ofatumumab. Blood. 2019;133:2031-42.

29. Barr PM, Robak T, Owen C, et al. Sustained efficacy and detailed clinical follow-up of first-line ibrutinib treatment in older patients with chronic lymphocytic leukemia: extended phase 3 results from RESONATE-2. Haematologica. 2018;103:1502-10.

30. de Jong J, Skee D, Hellemans P, et al. Single-dose pharmacokinetics of ibrutinib in subjects with varying degrees of hepatic impairment<sup/>. Leuk Lymphoma. 2017;58:185-94.

\section{Publisher's Note}

Springer Nature remains neutral with regard to jurisdictional claims in published maps and institutional affiliations.

\section{Ready to submit your research? Choose BMC and benefit from}

- fast, convenient online submission

- thorough peer review by experienced researchers in your field

- rapid publication on acceptance

- support for research data, including large and complex data types

- gold Open Access which fosters wider collaboration and increased citations

- maximum visibility for your research: over $100 \mathrm{M}$ website views per year

At $\mathrm{BMC}$, research is always in progress.

Learn more biomedcentral.com/submissions 